Sustainability 2015, 7, 811-830; doi:10.3390/su7010811

OPEN ACCESS

\title{
sustainability
}

ISSN 2071-1050

www.mdpi.com/journal/sustainability

Article

\section{Futures Analysis of Urban Land Use and Wetland Change in Saskatoon, Canada: An Application in Strategic Environmental Assessment}

Anton Sizo ${ }^{1, *}$, Bram Noble ${ }^{2}$ and Scott Bell ${ }^{3}$

1 Geography and Planning, University of Saskatchewan, 117 Science Place, Saskatoon, SK S7N 5C8, Canada

2 Geography and Planning, School of Environment and Sustainability, University of Saskatchewan, 117 Science Place, Saskatoon, SK S7N 5C8, Canada; E-Mail: b.noble@usask.ca

3 Geography and Planning, Spatial Initiative, University of Saskatchewan, 117 Science Place, Saskatoon, SK S7N 5C8, Canada; E-Mail: scott.bell@usask.ca

* Author to whom correspondence should be addressed; E-Mail: anton.sizo@usask.ca; Tel.: +1-306-954-4664.

Academic Editor: Marc A. Rosen

Received: 4 November 2014 / Accepted: 1 January 2015 / Published: 13 January 2015

\begin{abstract}
This paper presents a scenario-based approach to strategic environmental assessment (SEA) for wetland trend analysis and land use and land cover (LUC) modeling in an urban environment. The application is focused on the Saskatoon urban environment, a rapidly growing urban municipality in Canada's prairie pothole region. Alternative future LUC was simulated using remote sensing data and city spatial planning documentation using a Markov Chain technique. Two alternatives were developed and compared for LUC change and threats to urban wetland sustainability: a zero alternative that simulated trends in urban development and wetland conservation under a business as usual scenario, in the absence of prescribed planning and zoning actions; and an alternative focused on implementation of current urban development plans, which simulated future LUC to account for prescribed wetland conservation strategies. Results show no improvement in future wetland conditions under the city's planned growth and wetland conservation scenario versus the business as usual scenario. Results also indicate that a blanket wetland conservation strategy for the city may not be sufficient to overcome the historic trend of urban wetland loss; and that spatially distributed conservation rates, based on individual wetland water catchment LUC peculiarities, may be more effective in terms of wetland conservation. The paper also demonstrates the
\end{abstract}


challenges to applied SEA in a rapidly changing urban planning context, where data are often sparse and inconsistent across the urban region, and provides potential solutions through LUC classification and prediction tools to help overcome data limitations to support land use planning decisions for wetland conservation.

Keywords: strategic environmental assessment; environmental baseline assessment; scenario analysis; zero alternative; urban planning; wetland conservation; Markov Chain; land use; future analysis

\section{Introduction}

The majority of wetland alteration is driven by, or associated with, changes to land use and land cover (LUC) resulting from human-induced surface disturbance [1]. In recent years, urban growth and regional development have become significant drivers of LUC change, due to the direct and indirect effects of surface disturbances to wetland hydrology, geomorphology, and ecology [2,3]. Spatial planning, including urban planning and development zoning, is a key policy instrument designed to direct future land use and development actions [4], but such planning and policy instruments do not always provide for adequate consideration of the potential impacts of urban LUC change to wetlands. Strategic Environmental Assessment (SEA), the assessment and integration of environmental and sustainability considerations in policy, plan, or program (PPP) development and decision making [5,6], has gained considerable momentum in recent years as a proactive and spatially appropriate framework for assessing and shaping land use policies, plans, and development actions $[7,8]$, including urban and regional land use plans [9,10], and managing their impacts on wetlands [11].

The basic premise of SEA is that it helps ensure that PPPs are developed and operationalized in an environmentally sensitive way, and that land uses and development actions are implemented within a sustainability framework. SEA is about understanding the context of a PPP or strategy being developed and assessed, identifying and understanding key trends, and assessing future environmental and sustainable outcomes to help achieve strategic objectives [12]. Its application typically focuses on the identification and assessment of trends in environmental baselines, and the analysis of future outcomes or scenarios under different land use or disturbance conditions $[13,14]$, thus identifying desired outcomes and what is required to achieve those outcomes [15].

The development and assessment of current and future land uses via scenario analysis and LUC modeling are foundational to SEA in the context of spatial planning and development [16,17]. Such scenario-based approaches, which produce visions of future conditions with and without currently planned development actions or initiatives [18-20], are widely promoted as good-practice in the impact assessment literature and recognized as a means to help overcome the challenges associated with predicting future outcomes under uncertain planning conditions [13,16,21-23]. However, despite the variety of LUC models applicable to land use analysis that currently exist [24,25], as well as a number of available scenario-based approaches [21-23], their combined application in SEA is limited [26], particularly within the context of land use planning and assessment for managing impacts to urban wetlands [27,28]. Noble et al. [29] report that the majority of assessment methods and techniques applied 
in SEA are limited to a number of common, qualitative-based approaches and argue the need for more analytical-based, quantitative assessment methods to support SEA application in regional land use contexts.

This paper presents a scenario-based approach to SEA for wetland area change trend analysis and LUC modeling in an urban environment using a Markov Chain technique. The application is focused on the Saskatoon urban environment, a rapidly growing urban municipality in Canada's prairie pothole region. Specifically, this paper: (i) demonstrates a scenario-based methodology for assessing the impact of a business as usual scenario through simulation of future LUC, based on trend analysis of historical wetland and urban conditions; (ii) assesses the impact of the City's proposed urban growth and development plan; and (iii) undertakes a comparison of futures with respect to the implications for urban wetland conservation. In doing so, the objective is to advance SEA design and quantitative approaches for wetland conservation planning in urban environments.

The following section provides a brief review of the wetland assessment and LUC modeling for futures and trend analysis in SEA application for urban planning and development. This is followed by a description of the study area, data, and methods used for wetland baseline and futures assessment; finally, the study results are presented. The paper concludes with a discussion of the results, challenges, and further research to advance strategic assessment methods for land use planning assessment in an urban wetland context.

\section{SEA Context: Wetlands Assessment and LUC Modeling}

The environmental significance of wetlands is well recognized: wetlands provide habitat for a large number of species, serve as flood control areas, and support ecosystems in terms of water quality maintenance, nutrient cycling, and carbon sequestration [1]. Despite this, wetlands are decreasing more rapidly than any other type of ecosystem [30,31]. Currently, only about 5-8 percent of Earth's land surface is covered by wetlands - about 14 percent of Canada is wetlands [32,33]. In the context of the Canadian prairie region, a reported 71 percent of wetlands have been lost, due primarily to agricultural land conversion but also due to road development and urban growth [3,11,31].

According to Rubec and Hanson [34], the Canadian Federal Policy on Wetland Conservation (FPWC) is intended to ensure an appropriate level of wetland conservation, the mitigation of environmental impacts to wetlands, and to sustain wetland functions. The FPWC applies to federal land, all activities on it, and all programs, expenditures, and decisions under federal jurisdictions. However, the majority of wetlands in Canada are on privately owned agricultural land [35], or in and surrounding urban municipalities, which makes both federal and provincial wetland protection policy largely ineffective.

Further, despite numerous policy and regulatory initiatives in Canada that relate to wetlands, there are no standardized or formal methods for the assessment and mitigation of the environmental impacts of development and land use decisions on wetlands $[3,34]$. The tool most often applied to wetland impact assessment and mitigation planning in Canada is project based Environmental Assessment (EA). However, Noble et al. [33], Seitz et al. [36], and Nielsen et al. [3] report that a considerable number of proposed activities, which potentially affect wetlands directly and/or indirectly, including urban growth and expansion, are either not classified as significant enough to trigger EA or are not subject to formal EA regulation. When EA is conducted, assessments are often of the "screening-type", designed for 
formulaic projects with seemingly predictable impacts, and EA is often conducted perfunctorily, which is both spatially and temporally restrictive $[11,33]$.

The development and application of tools for the assessment of LUC change and potential impacts on wetlands can methodologically improve EA for the sustainable management of wetlands in urban environments. LUC change is broadly defined as a spatiotemporal iteration between biophysical and human related drivers [37]. A variety of LUC change models are available for representation of LUC dynamics, its causes, and possible consequences. Schrojenstein Lantman et al. [38] propose four core principles of LUC change modeling, where any given LUC change model is based on at least one principle:

(i). Historical trends. This principle is based on extrapolation of past LUC change, assuming permanency of the factors that underline the trend.

(ii). Suitability. The suitability principle describes LUC change based on the specific characteristics of a parcel of land (e.g., spatial, biophysical, or socio-economical preference) in terms of quantitative or qualitative based minimization of costs or maximization of profit.

(iii). Neighborhood interaction. The basis of this principle is that the possibility of land change depends on surrounding land uses and use characteristics. LUC change drivers in this case can be biophysical or socio-economic.

(iv). Actor interaction. In this principle, LUC change depends on the decision-making process, which is the result of actors' interaction. The drivers are socio-economic values and development policy.

Regardless of the principles behind a LUC change model, there are several considerations for any LUC model application [24,25], namely: land use history, temporal dynamics of land use, and the trajectory of land use changes; representative driving factors for a particular LUC change model; land use patterns, their spatial interaction and neighborhood effects; level of analysis and its complexity; scale, including spatial and temporal scale, model granularity, and analytical dimensions. The weight of a consideration given to any set of considerations can vary depending on the particular LUC change model, the goals of the application, and practical constraints.

There are several underlying analytical approaches that are used most often in LUC change model applications, including: cellular automata, statistical analysis, Markov Chain, artificial neural networks, economic-based models, and agent-based model [38]. Any one of these analytical approaches can be based on one or more of principles described above and a number of them can be combined in any given LUC model. In the context of wetlands assessment, a Markov Chain approach, which is based on a historical trend principle, is a convenient and accurate model for LUC simulation and has been adopted in several simulation-based studies (see for example Zhang et al. [39], Arsanjani et al. [40], and Ma et al. [28]). However, the benefits of such an approach to assessing scenarios of wetland change in urban development have not been explored within the context of SEA application.

\section{Study Area}

The city of Saskatoon is located in the province of Saskatchewan, Canada, on the banks of the South Saskatchewan River. The province of Saskatchewan is part of the prairie pothole region, which covers approximately 480,000 $\mathrm{km}^{2}$ [1] and contains approximately 11 percent of Canada's wetlands [41]. 
Saskatoon is the largest city in the province of Saskatchewan with an estimated population of 254,000 as of 30 June 302014 [42]. From the first permanent settlements in 1883, the city of Saskatoon has grown steadily [43]; 1951-2011 was historically the period of fastest growth, with an average annual rate of population increase of $2.6 \%$ [44,45], and with a projected population of 387,742 (with annual growth rate of $2.5 \%$ ) to 2032 [46].

The study area consists of five development sectors situated in the Suburban Development Areas of the city of Saskatoon. The development sectors are identified in the City of Saskatoon's Official Community Plan Bylaw No. 8769 [47] and with planning documentation (Sector Plans) publicly available [48]. However, publicly available Sector Plans do not fully reflect the most current planning strategy for the city. As such, the Sector Plan boundaries for each development area were updated based on discussions with the City of Saskatoon Planning and Development Department, taking into consideration the City's most current development strategy. Next, following Sizo et al. [49], the Sector Plans were then adjusted to the next closest (in terms of spatial extent) water catchments (land area that drains to a common waterbody, e.g., river or wetland)—referred hereinafter as assessment areas (Figure 1). These are considered the smallest geographically and ecologically meaningful regions for a regional level environmental assessment [50]. A water catchment was chosen for this assessment as it represents the minimum hydrological unit in terms of the ability of a wetland's system to maintain its functions and stability over the long-term [2,51].

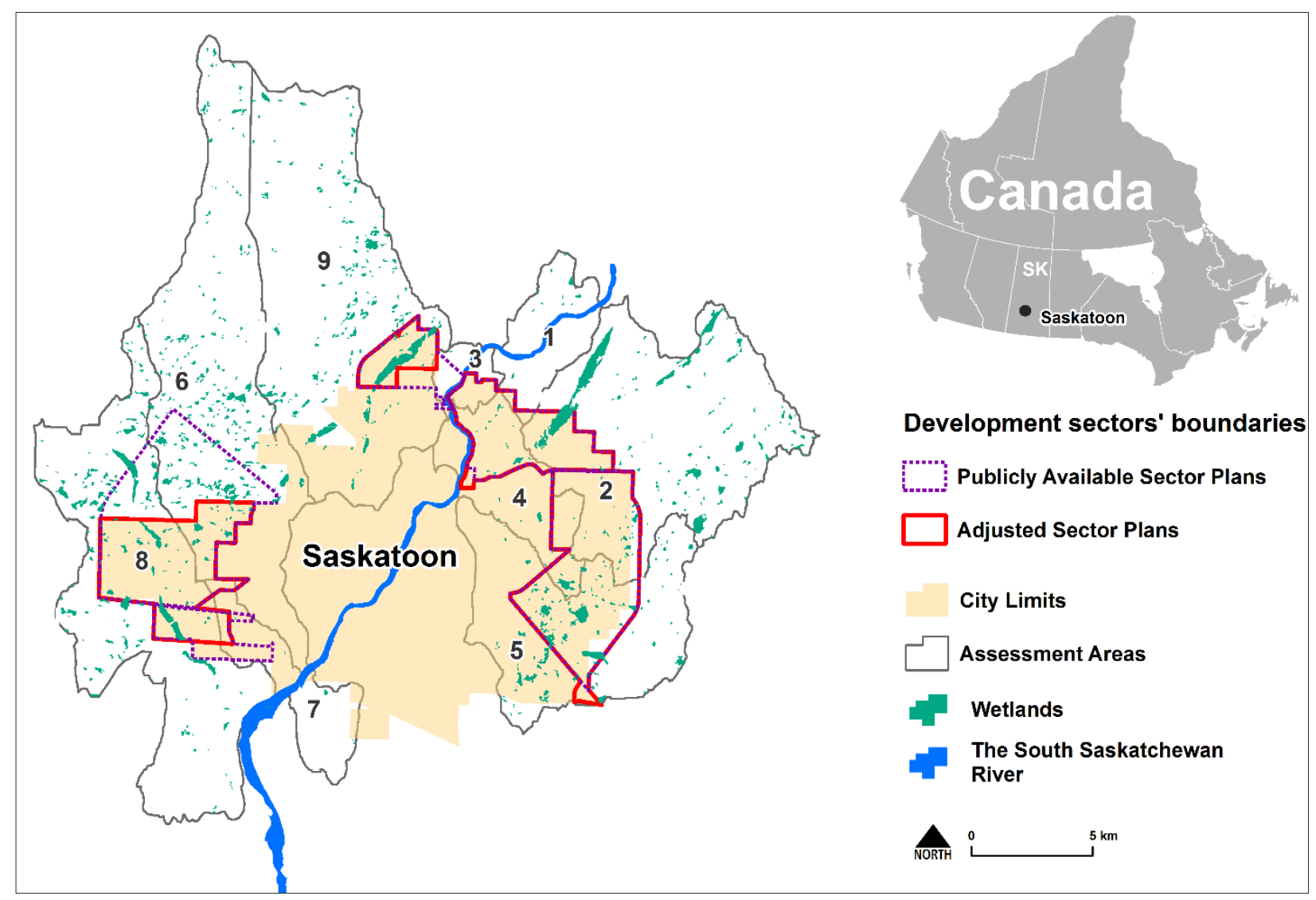

Figure 1. Saskatoon urban environment study area and adjusted sector plan areas (assessment areas). 
The assessment areas contain approximately 1870 ha of wetlands, including about 506 ha of wetlands within the updated Sector Plans' area [49]. The future growth of the city will have both direct and indirect impacts on urban lands, including wetland areas. Similar to other urban municipalities across Canada, the impacts of urban development on wetlands under planned urban development activity is not subject to SEA under current federal or provincial laws or regulations [33].

\section{Assessment Approach}

Baseline assessment is a key step in any SEA application that serves to establish the regional context for an assessed policy, plan, or program, and consists of an analysis of baseline conditions and changes across space and/or over time. Baseline assessment is arguably the most data and ancillary information intense stage of the SEA process, and is fundamental to the overall analytical quality of SEA and the reliability of SEA results [6,8,52-56]. Using the information from a baseline assessment, the scenario assessment and evaluation stage of SEA identifies and evaluates the potential impacts of strategic alternatives, or development scenarios, on current baseline conditions. A zero alternative or business as usual scenario describes a future without planned action and serves as a future baseline condition for comparison with potential impacts from planned activities, and is a required component of good SEA practice $[6,8,18-20,55,56]$. Two alternative scenarios were developed and assessed for the study area: (i) a zero alternative, based on a trend analysis of historical wetland and urban change data; and (ii) a current development plan (CDP) scenario, which was based on considering the current development plans and growth strategy for the City of Saskatoon. A discrete-time Markov Chain technique was applied for simulation of future LUC within the study area under each scenario.

\subsection{Data}

The assessment incorporated historic LUC change data and data from a landscape based temporal analysis of wetland change in the Saskatoon urban development region [49]. The assessment of LUC change was limited to three classes: (i) wet area; (ii) built-up area; and (iii) non built-up area. Wet area was used as a proxy for wetlands and consists of open water or saturated areas without taking into account morphological properties of the soil [57]. Built-up area captured urban development features and associated structures (e.g., housing units, schools) [58]. All other areas, which were not identified as wet area or built-up area, were classified as non built-up areas.

Historic LUC change data covered 1985-2011, and three Landsat 5 TM Climate Data Record Surface Reflectance datasets [59] were used as remote sensing (RS) data sources. The selection of RS data was based on image quality, availability, and seasonality. Spring images were preferred, as suggested by Dahl and Watmough [60] for wetland identification in Canada prairie region. The acquisition dates for RS images were: May 11, 1985, April 28, 2006, and May 19, 2011. The post classification comparison method was used for LUC change data extraction in the form of a change detection table (Table 1). RS unsupervised classification method was used for the image classification with a resulting overall accuracy of $92.4 \%$ for $1985,93.6 \%$ for 2006 , and $92.0 \%$ for 2011 , and Khat coefficients of $0.884,0.903$, and 0.878 , respectively [49]. Change detection data was used as a LUC area transition matrix for subsequent Markov Chain models. 
Table 1. Land use and land cover (LUC) change data (area transition matrix).

\begin{tabular}{|c|c|c|c|c|c|c|c|}
\hline \multirow{2}{*}{$\mathbf{A A}$} & \multirow{2}{*}{ LUC class } & \multicolumn{3}{|c|}{ 1985-2006 } & \multicolumn{3}{|c|}{ 1985-2011 } \\
\hline & & Built-up & Non Built-up & Wet Areas & Built-up & Non Built-up & Wet Areas \\
\hline \multirow{3}{*}{1} & Built-up & 0.0 & 1.4 & 0.0 & 0.0 & 1.4 & 0.0 \\
\hline & Non built-up & 50.9 & 1422.8 & 0.1 & 1.4 & 1442.3 & 17.6 \\
\hline & Wet areas & 0.1 & 45.1 & 14.0 & 0.0 & 29.3 & 29.9 \\
\hline \multirow{3}{*}{2} & Built-up & 4.3 & 25.6 & 0.4 & 3.8 & 26.0 & 0.5 \\
\hline & Non built-up & 27.5 & 7172.4 & 72.1 & 20.3 & 7101.4 & 150.3 \\
\hline & Wet areas & 2.3 & 119.4 & 360.8 & 0.9 & 140.5 & 341.2 \\
\hline \multirow{3}{*}{3} & Built-up & 10.1 & 15.9 & 0.0 & 7.4 & 18.5 & 0.0 \\
\hline & Non built-up & 10.1 & 508.1 & 0.0 & 0.9 & 502.9 & 5.5 \\
\hline & Wet areas & 0.0 & 9.5 & 0.5 & 0.0 & 5.6 & 4.4 \\
\hline \multirow{3}{*}{4} & Built-up & 116.7 & 27.1 & 0.0 & 113.6 & 30.2 & 0.0 \\
\hline & Non built-up & 208.0 & 1826.2 & 8.8 & 385.1 & 1631.3 & 21.5 \\
\hline & Wet areas & 5.9 & 20.5 & 39.3 & 14.2 & 19.6 & 32.0 \\
\hline \multirow{3}{*}{5} & Built-up & 568.9 & 68.9 & 0.0 & 581.6 & 56.1 & 0.1 \\
\hline & Non built-up & 615.1 & 3680.1 & 36.1 & 734.5 & 3533.5 & 63.3 \\
\hline & Wet areas & 61.7 & 101.9 & 196.5 & 66.3 & 96.6 & 197.1 \\
\hline \multirow{3}{*}{6} & Built-up & 752.4 & 118.1 & 0.0 & 769.9 & 95.0 & 5.4 \\
\hline & Non built-up & 124.6 & 6924.4 & 50.7 & 272.2 & 6531.0 & 296.1 \\
\hline & Wet areas & 0.8 & 395.4 & 301.6 & 3.9 & 323.6 & 370.4 \\
\hline \multirow{3}{*}{7} & Built-up & 230.0 & 59.6 & 0.0 & 233.3 & 55.4 & 0.0 \\
\hline & Non built-up & 110.2 & 1222.5 & 3.6 & 146.4 & 1176.1 & 11.2 \\
\hline & Wet areas & 1.4 & 5.5 & 1.7 & 1.9 & 3.4 & 3.2 \\
\hline \multirow{3}{*}{8} & Built-up & 41.4 & 34.5 & 0.0 & 47.3 & 28.5 & 0.0 \\
\hline & Non built-up & 63.5 & 7500.2 & 49.1 & 109.5 & 7213.4 & 279.9 \\
\hline & Wet areas & 0.0 & 122.6 & 351.7 & 0.0 & 62.9 & 411.4 \\
\hline \multirow{3}{*}{9} & Built-up & 710.8 & 169.5 & 1.4 & 762.7 & 117.8 & 1.3 \\
\hline & Non built-up & 407.9 & 7420.6 & 79.7 & 804.4 & 6986.6 & 117.2 \\
\hline & Wet areas & 26.5 & 433.6 & 302.0 & 61.7 & 407.0 & 293.5 \\
\hline \multicolumn{8}{|c|}{ Area unit is ha } \\
\hline
\end{tabular}

\subsection{Simulation of Future LUC: Markov Chain Technique}

The Markov Chain technique is a stochastic model and can be defined as a set of states, $S t=\left\{S t 0, S t_{t}\right.$, $\left.S t_{2}, \ldots, S t_{n}\right\}$, where the modeled process moves from one state to another in a series of steps with a denoted transition probability $p_{i j}$. When a transition matrix $P=\left[p_{i j}\right]$ is defined, each element of the matrix, $p_{i j}$, shows the probability of land use area change from type $i$ in time period $n-1$ to type $j$ in time period $n$, with $R$ total number of land use types:

$$
\mathbf{P}=\left[\begin{array}{cccc}
\mathbf{p}_{11} & \mathbf{p}_{12} & \cdots & \mathbf{p}_{1 \mathrm{R}} \\
\mathbf{p}_{21} & \mathbf{p}_{22} & \cdots & \mathbf{p}_{2 \mathrm{R}} \\
\vdots & \vdots & \ddots & \vdots \\
\mathbf{p}_{\mathrm{R} 1} & \mathbf{p}_{\mathrm{R} 2} & \cdots & \mathbf{p}_{\mathrm{RR}}
\end{array}\right]
$$

Using the probability matrix in the initial state, it is possible to calculate the state transition probabilities from the initial state to the $n^{\text {th }}$ state: 


$$
\mathbf{P}_{\mathrm{ij}}^{(\mathbf{n})}=\sum_{\mathbf{k}=\mathbf{0}}^{\mathbf{R}-\mathbf{1}} \mathbf{P}_{\mathrm{ik}} \mathbf{P}_{\mathbf{k j}}^{(\mathbf{n}-\mathbf{1})}
$$

The probability matrix was calculated based on the LUC area transition matrix (Table 1), using the following formula:

$$
\mathbf{P}_{\mathrm{ij}}=\frac{\mathbf{A}_{\mathrm{ij}}}{\sum_{\mathbf{j}} \mathbf{A}_{\mathrm{ij}}}
$$

where $A_{i j}$ is the area of land use type that has been in state $i$ in period $t-1$ and is in state $j$ in period $t$.

The initial state matrix, defined as $S t(0)$, identifies the starting situation - the current state of the baseline environment. The future land use distribution was predicted based on the initial state matrix and transition probability, using a Markov Chain simulation model $S t(n)$

$$
\operatorname{St}(\mathbf{n})=\mathbf{S t}\left(\mathbf{n - 1 )} \times \mathbf{P}^{(1)}=\mathbf{S t}(\mathbf{0}) \times \mathbf{P}^{(\mathbf{n})}\right.
$$

In Equation (4), $n$ is the relation between desired time period and observation length:

$$
\mathbf{n}=\frac{\mathbf{L}_{\mathbf{d}}}{\mathbf{L}_{\mathbf{o}}}
$$

where $L_{d}$ is the desired time period (for a land use prediction) and $L_{o}$ is observation length.

For computation of the probability matrix $P^{(n)}$ the spectral decomposition approach was applied, where matrix $P$ was represented by its eigenvalues (EigVal) and eigenvectors (EigVect):

$$
P=\text { EigVect } \times \text { EigVal } \times \text { EigVect }^{-1}
$$

and respectively:

$$
\mathbf{P}^{(\mathbf{n})}=\text { EigVect } \times \text { EigVal }^{\mathbf{n}} \times \text { EigVect }^{-1}
$$

where

$$
\operatorname{EigVal}^{\mathbf{n}}=\left[\begin{array}{cccc}
\lambda_{1}^{\mathrm{n}} & \mathbf{0} & \cdots & \mathbf{0} \\
\mathbf{0} & \lambda_{2}^{\mathrm{n}} & \cdots & \vdots \\
\vdots & \vdots & \ddots & \mathbf{0} \\
\mathbf{0} & \cdots & \mathbf{0} & \lambda_{\mathrm{m}}^{\mathrm{n}}
\end{array}\right]
$$

and $\lambda_{m}$ is the $m^{\text {th }}$ eigenvalue and associated with $m$ column of EigVect. The negative eigenvalues when appeared were replaced by zero [61]. The initial state matrix $S t(0)$, based on LUC data for the assessment areas, was defined as:

$$
\operatorname{St}(0)=\left[\begin{array}{c}
A_{b} \\
A_{n b} \\
A_{w}
\end{array}\right]=\left[\begin{array}{c}
\text { Built }- \text { up } \\
\text { Non built }- \text { up (other) } \\
\text { Wet areas }
\end{array}\right]
$$

where $A$ is the area for a respective LUC class.

\subsection{Markov Chain Models and LUC Alternatives}

Two Markov Chain LUC simulation models were developed using 1985 LUC data based St(0): (i) MC1985-2006, using a 1985-2006 probability matrix, and (ii) MC1985-2011, using a 1985-2011 probability matrix. The MC1985-2011 model was used for a quality assessment of the Markov Chain 
technique, while the MC1985-2006 model was used for scenario development. Two alternative scenarios were developed for the future analysis:

(i) The zero alternative, which simulates business as usual, where future LUC is based on historical trends in wetland/urban change using the MC1985-2006 model for the entire study area and describing future conditions without the introduction of planned urban development actions.

(ii) The current development plans (CDP) alternative, which describes future conditions assuming the City's development plans and strategy are implemented, using the MC1985-2006 model for the area which lies outside the spatial extent of the proposed Sector Plans of urban development.

\subsection{Quality Assessment of Markov Chain Simulation}

The assessment was performed for the built-up class, as wetness condition (and respectively wet area change tendency) changed significantly between 1985 and 2011 [62]. The simulated MC1985-2011 model LUC area for 2006 was compared with results of 2006 RS images classification. The Relative Error (RE) was calculated for each assessment area as follows:

$$
\mathbf{R E}=\frac{\left|\mathbf{X}_{\mathbf{o}}-\mathbf{X}_{\mathbf{p}}\right|}{\mathbf{X}_{\mathbf{o}}}
$$

where $\mathrm{X}_{\mathrm{o}}$ are the original values (the result of the $2006 \mathrm{RS}$ classification) and $\mathrm{X}_{\mathrm{p}}$ are modeled values (the results of the MC1985-2011 simulation for 2006). The accuracy assessment for the model yielded good overall average and median accuracy of $66.3 \%$ and $69.1 \%$, respectively (Figure 2), with one outlier in assessment area \#1 (more than two standard deviations).

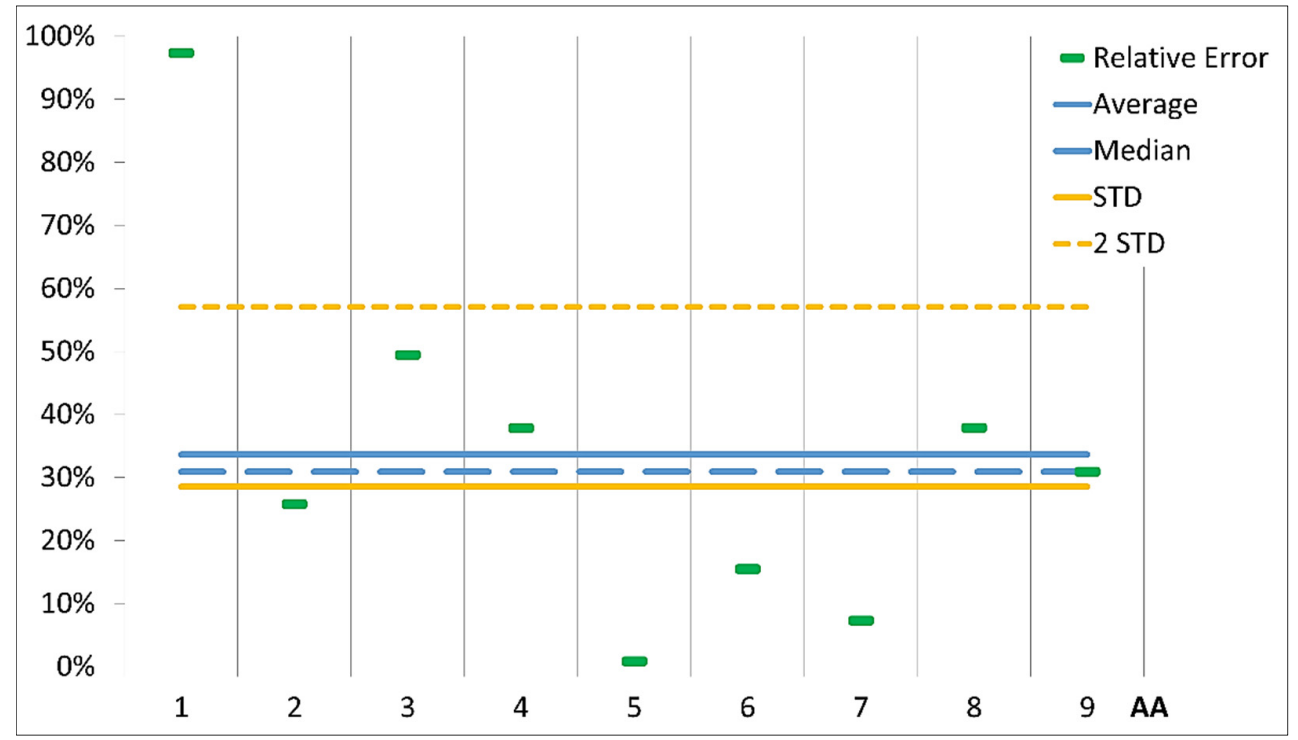

Figure 2. Quality assessment of Markov Chain simulation (built-up class).

\subsection{City Planning and Neighborhood Urban Development Evaluation}

The City of Saskatoon's Official Community Plan Bylaw No. 8769 identifies the temporal scope of CDP application not by year but with a population threshold of 500,000 [47]. As such, to calculate an 
end date for the CDP for modeling purposes, the City of Saskatoon Population Projection data [46] was used. The projection report covered 2012-2032; the report's population estimations for the years 2012, 2017, 2022, 2027, and 2032 (assuming annual growth rate 2.5\%) were extrapolated using a 2nd order polynomial regression to the population level of 500,000, which resulted in the year 2043. The expected scope of planned development over the next 30 years was confirmed by discussions with a senior planner at the Planning and Development Branch, the City of Saskatoon.

To assess future LUC for the CDP alternative, the following steps were performed (Figure 3): first, the updated Sector Plan area (the area of proposed urban development) was removed from the assessment areas and reclassified; second, the MC1985-2006 model was applied to the rest of the assessment area to simulate future LUC to the end date of the expected scope of planned development; and, finally, reclassification results of the Sector Plans and the MC1985-2006 simulation for the remaining assessment areas were combined as the CDP alternative. Please see details below.

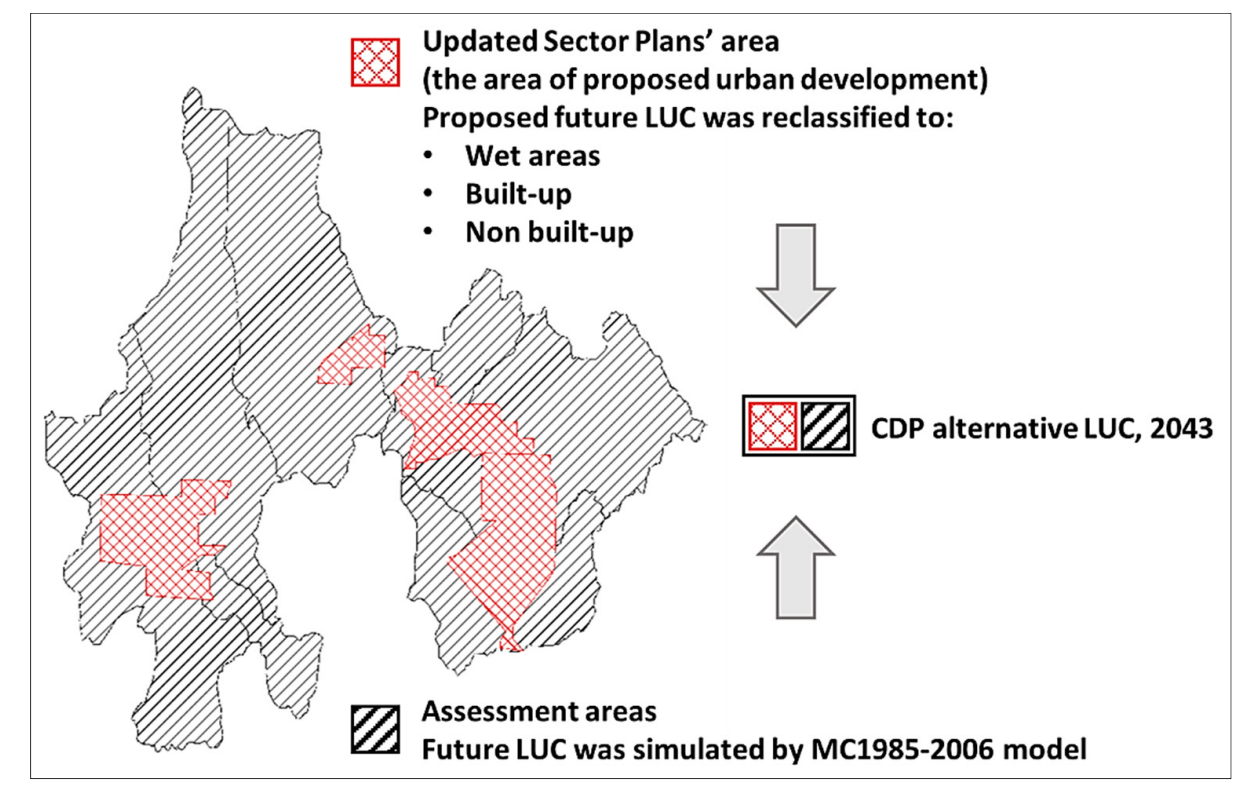

Figure 3. Current development plan (CDP) alternative LUC simulation.

The planning and development documentation for the City (bylaws and Sector Plans) were prepared in different years and with different levels of detail contained in each plan. Some planning areas (e.g., Blairmore, University Heights, and Holmwood) contained only neighborhood outlines; four neighborhoods (Kingston, Aspen Ridge, Brighton, and Rosewood) had very detailed Sector Plans, containing street details and neighborhood housing/land use block boundaries; the North Sector plan for the city contained the lowest level of planning detail, where only the boundary of planned development with the area was identified (Figure 4).

To compensate for the difference in the level of planning details provided across the Sector Plans, and to include the most current planning strategy in the LUC simulation, LUC within the Sector Plans was reclassified into three classes: wet areas, built-up, and non built-up. The residential, business, and industrial areas were classified as built-up. Water and storm water ponds and constructed wetlands (where specified) were classified as wet areas. Wet areas also included: RS identified wet areas within development sectors where no land alteration had been planned for the next 30 years; and wet areas 
located in west, north, and north-east swales that had been directly identified for conservation. All other areas were classified as non built-up.
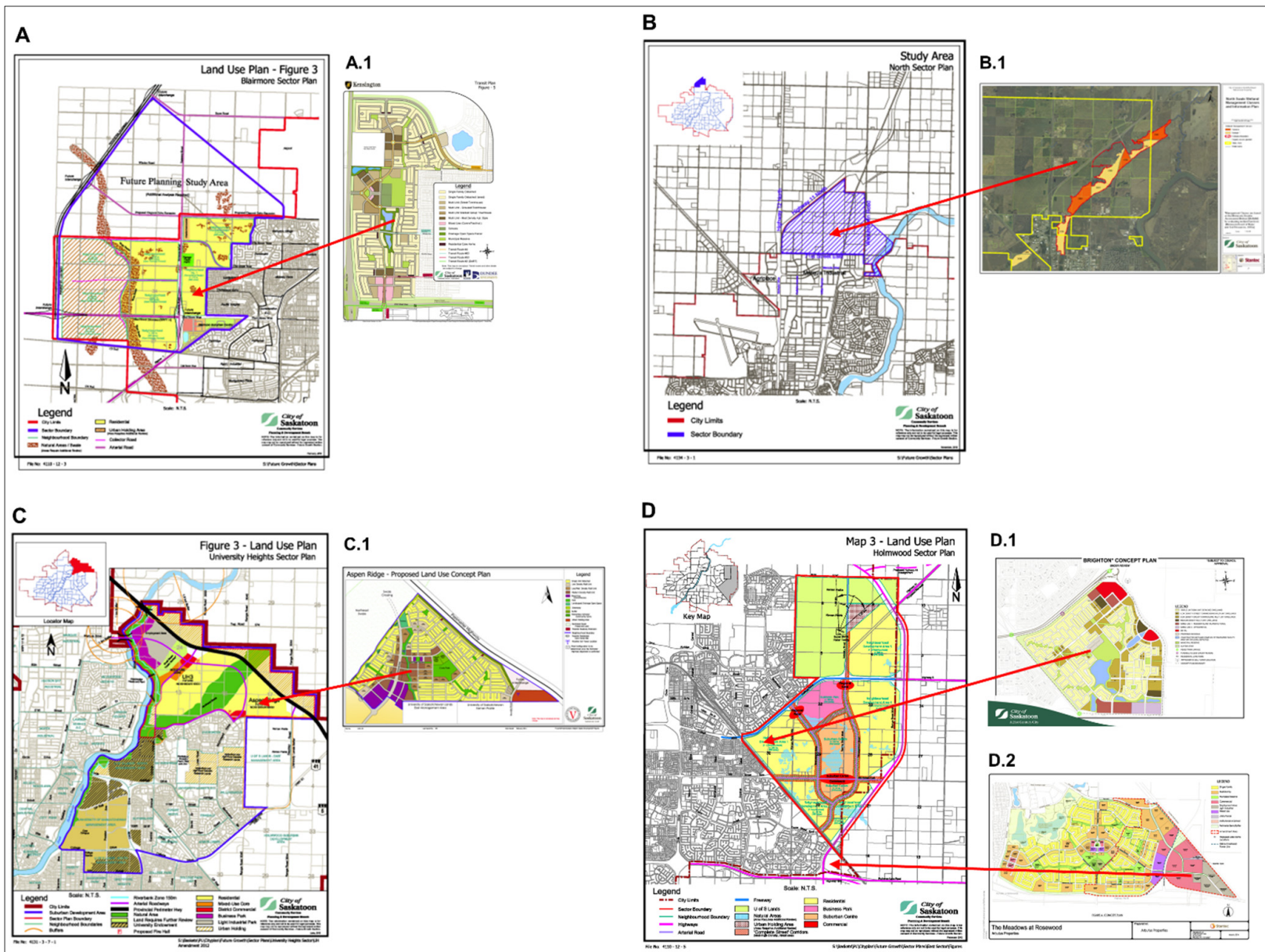

Sector Plans: A - Blairmore, A.1 - Kensington; B - North Sector, B.1 - Zonal screening; C - University Heights, C.1 - Aspen Ridge; D - Holmwood, D.1 - Brighton, D.2 - Rosewood.

Figure 4. Sector Plans' LUC, publicly available for the study area (overview, please see [48] for original maps).

The reclassification scheme was reviewed and discussed with the City of Saskatoon Planning Department for confirmation of the most current planning strategy and data available. As a result, a number of suggestions were added to the reclassification results (Figure 5):

(i) In the neighborhoods with detailed plans, open space areas (e.g., parks) were identified as non built-up; constructed wetlands, conserved wetlands with original boundaries, and water/storm ponds were identified as wet areas; all other areas were identified as built-up.

(ii) Neighborhood areas without detailed plans were classified as built-up with a variable rate of non built-up: (1) $0 \%$ and 5\% for non residential and (2) 10\% for residential use. The neighborhoods without wet areas that were directly prescribed for conservation (e.g., west and north swale) were identified for conservation of $30 \%$ of existing wet areas per neighborhood. 


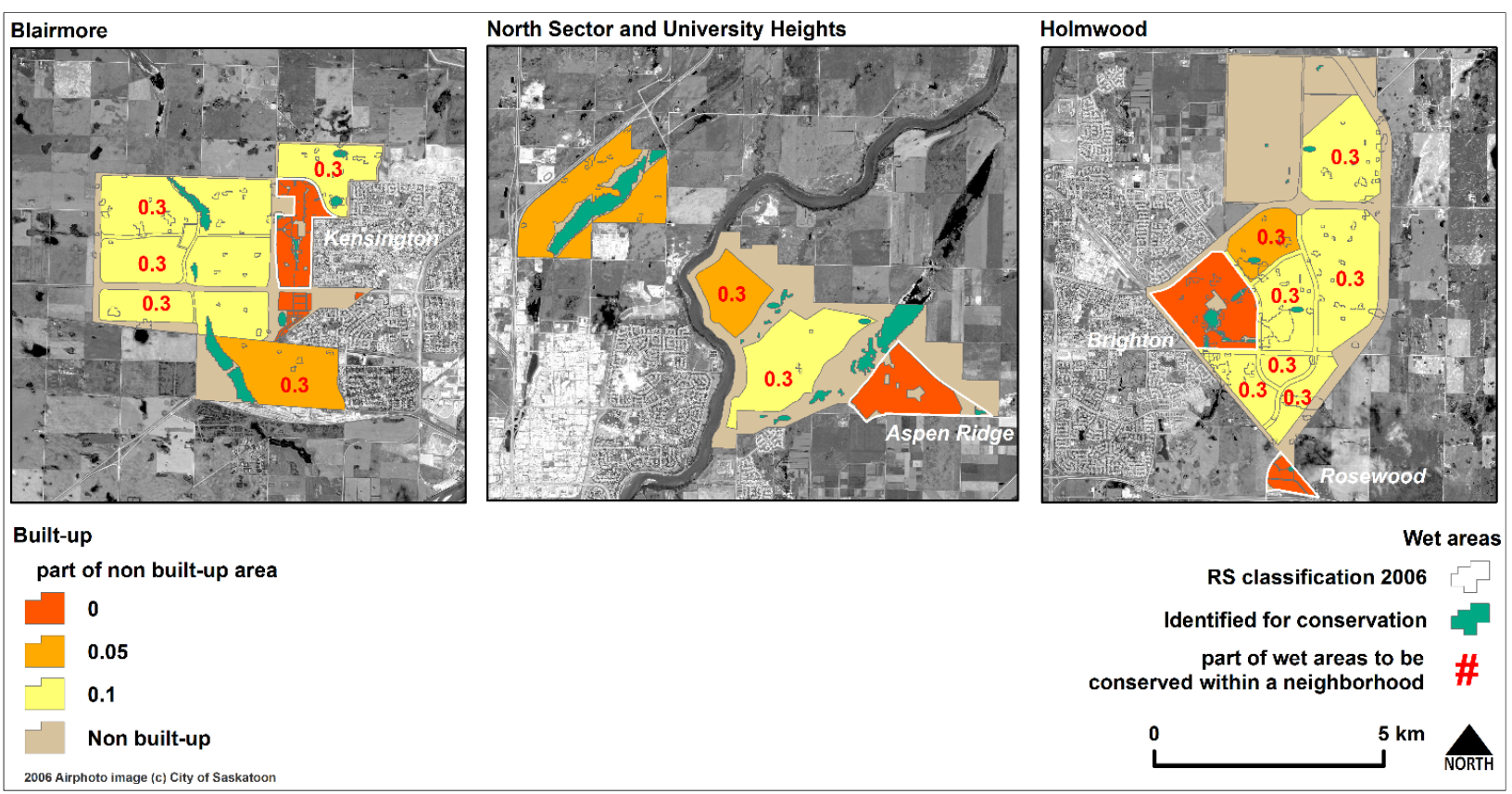

Figure 5. Reclassification of Sector Plans’ LUC.

\section{Results}

The comparison of simulated wet areas with historical data (Figure 6) shows a steady decrease in wet area for most of the study area, and simulated values are below the 5\% average wetland area threshold for temperate-zone watersheds, suggested by Mitsch and Gosselink [63]. Wetland area is a major indicator for wetland habitat evaluation, as it is reasonable to assume that the loss or degradation of wetland area negatively affects the ability of wetlands in a watershed to maintain their functions within a water catchment, including adequate flood control, water quality maintenance, and support efficient wildlife habitat $[60,63]$.

The CDP and zero alternatives identify and estimate future LUC change in the study area. The wet areas simulated for the zero alternative scenario considered the historical trend of wetland/urban change in the study area, while the simulation for the CDP alternative included the most recent development Sector Plans and the City's current development strategy for the next 30 years. The comparison of wet area simulation between the two alternatives shows that five of the nine assessment areas (i.e., adjusted Sector Plan areas) have a less than $0.1 \%$ difference in wet area (\# 1, 3, 4, 7, and 8); three assessment areas show a difference between scenario conditions of $0.15 \%$ and $0.3 \%$ (\# 2, 6, and 9); and assessment area \# 5 resulted in the most difference between scenarios, with a $0.67 \%$ difference in wet area. For the entire study area, the 2043 wet area under the zero alternative is $2.59 \%$ and for the CDP alternative is $2.56 \%$. Overall, the 2043 simulation results for wet areas are close, which may indicate that the wetland conservation strategy, identified in the CDP, will have little overall effect on wet area when compared to business as usual under the zero alternative. Part of the challenge is that the City's planning initiatives, including wetland conservation strategies, are bounded by administrative units, which is often the case for urban development [64], as opposed to capturing wetland functional scales [17], which were 
considered in this analysis and may be considered minimal spatial units in terms of ensuring the ability of wetlands to maintain their long-term functions and resiliency in urban environments [2,51].

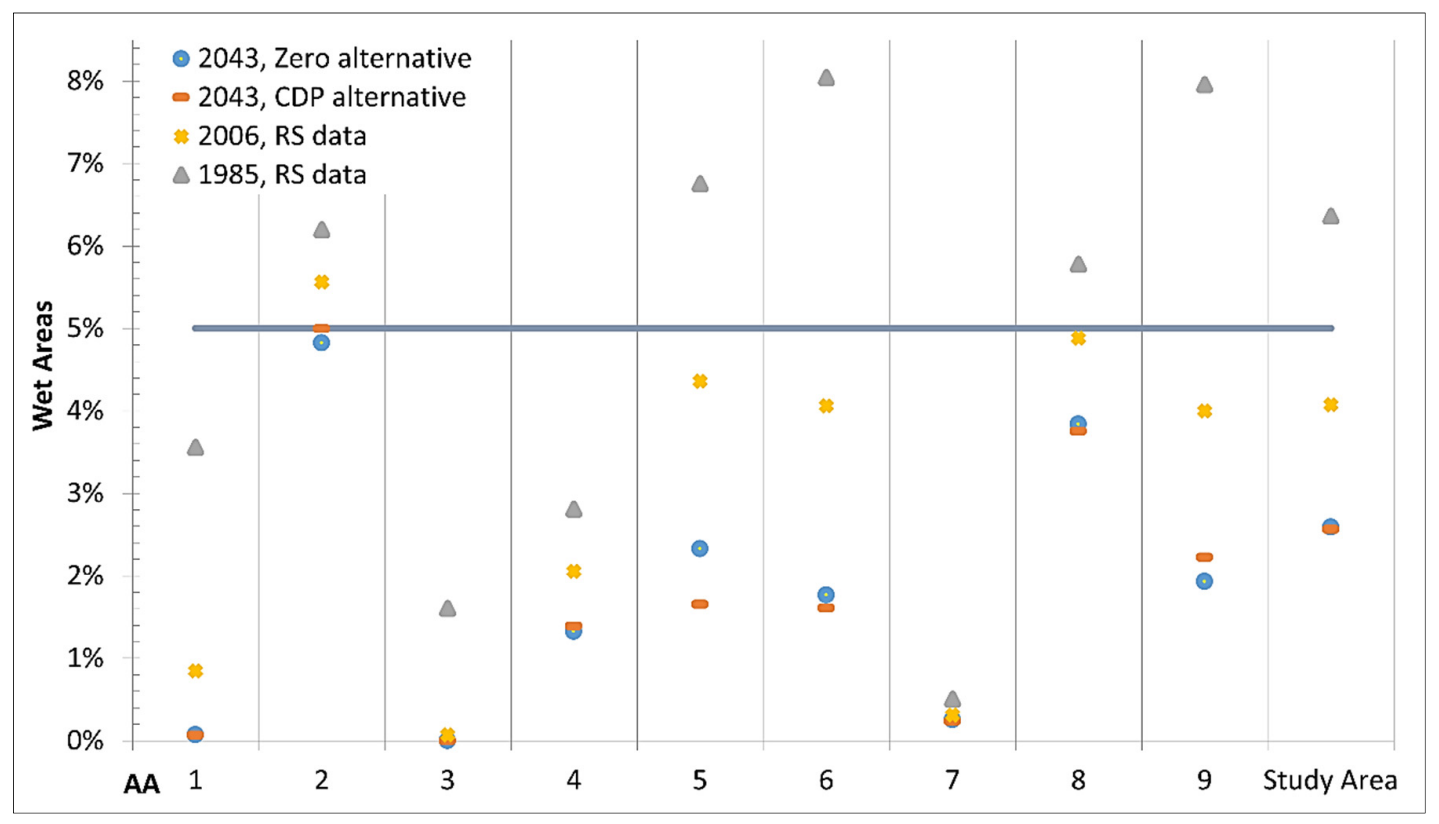

Figure 6. CDP and zero alternatives wet areas comparison.

The Markov Chain technique itself is not an explicit spatial analysis method. However, it is possible to examine the spatial variability of wet area conservation trends among assessment areas. It can be done through an investigation of the spatial distribution of differences between the CDP and the zero alternative with regard to wet areas Markov Chain simulation, despite the close simulation result overall (for the study area). This allows identification of areas where the current development strategy either benefits (assessment areas with positive difference, i.e., \#2, 3, 4, and 9) or does not benefit (with negative difference, i.e., \# 1, 5, 6, 7, and 8) from the city's proposed wetland conservation strategy, compared to the historical trend (Figure 7). The variability in net benefits indicates that, in terms of ensuring wetland conservation improvements, a unified strategy as identified under the CDP may not be effective for all urban planning units within city boundaries. Rather, what may be required is a diversity of conservation plans within the study area, where the planning strategy respects overall wetland vulnerability by water catchment, e.g. considering existing wetland/urban patterns, overall wetland area, size, and distribution.

\section{Discussion}

Appropriately managing the potential impacts of urban development on wetlands requires an understanding of trends in environmental baselines and some forethought and foresight about future urban growth and resulting LUC conditions. Scenario-based assessment is foundational to SEA [16,21-23]; however, its application, quantitatively, and supporting methods and tools have been relatively limited [29]. Consideration of a zero alternative (business as usual scenario) can provide a vision of a future without currently planned development actions, and support the comparison of the impacts of future outcomes with those of planned activities [18-20]. 


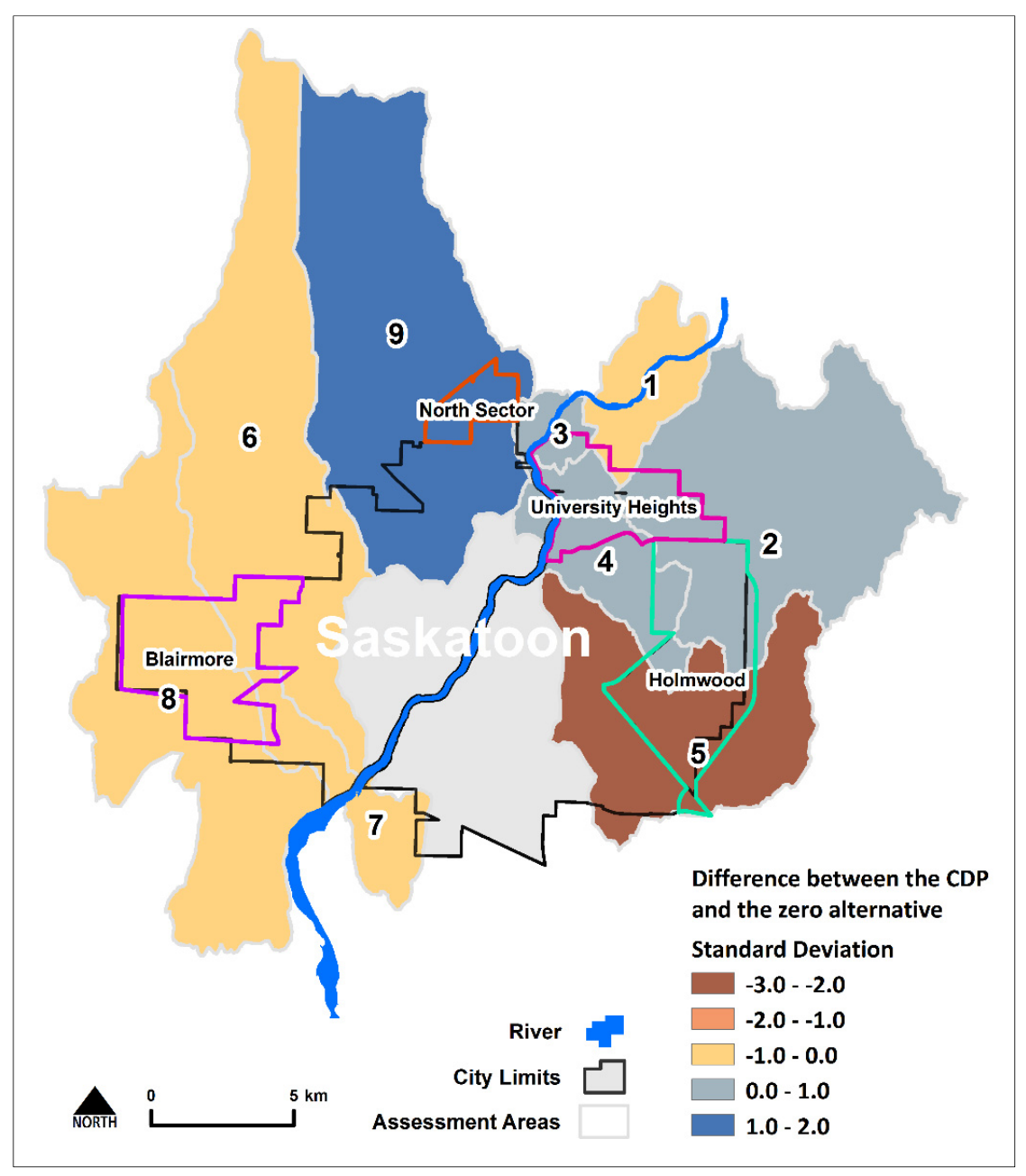

Figure 7. Difference of wet areas Markov Chain simulation between the CDP and the zero alternatives.

It could be argued that there is a need for consistent and complete baseline data to support sophisticated future trends analysis in SEA applications. Schrojenstein Lantman et al. [38] noted that consistent data is a precondition for good LUC modeling. Unfortunately, as was found during this research, consistent and comprehensive datasets are rarely available in actual urban planning contexts. Publicly available planning data is often not up-to-date, particularly in fast-growing municipalities such as the one in this study and as such may not actually reflect the most current planning and development strategy. González et al. [65] reported that impact assessment with the use of GIS techniques is widely constrained by the level of detail of available datasets. However, Therivel [6] argued that "not all the baseline data must be available for an SEA to proceed;" João [66] agreed, in that SEA can be completed with missing baseline data and argues that there is a need to reach a balance between data collected and data needed. The current study used development plans proposed to establish a development strategy for the city of Saskatoon for the next 30 years. Each of the neighborhood or land use Sector Plans, however, contained varying levels of planning detail. As such, to facilitate trends analysis and scenario development, it was necessary to supplement and standardize the granularity of data and land use 
classification based on more qualitative data, based on discussion and recommendations from the representatives of the City's Development and Planning Department.

A Markov Chain, a stochastic method, was then used for LUC simulation. A stochastic approach is recommended against others to account for the uncertainty and variability associated with future conditions (see for example MacDonald [67]). However, as with all futuring methods, the Markov Chain has its limitations [68]. The probability distribution of the next period's state depends on the current state and does not depend on the states the chain had previously passed through. That means the variation of the probability of change between two states is not a part of the Markov Chain model and is not reflected in the simulation of future. Also, as the transition probability determination plays an important role in Markov Chain modeling, the accuracy of the input data needs careful consideration. In terms of the current study, the probability matrix was calculated from the area transition matrix, based on RS change analysis of the study region, with an overall accuracy of $92.4 \%$ for $1985,93.6 \%$ for 2006 , and $92.0 \%$ for 2011 , and Khat coefficients $0.884,0.903$, and 0.878 , respectively [49]. If feasible, the quality assessment of the Markov Chain model should be performed for the area of application. For the study area, the MC1985-2011 model was evaluated with a good overall average and median accuracy of $66.3 \%$ and $69.1 \%$, respectively. Another assumption of the Markov Chain technique is that the probability law relating the next period's state to the current state does not change. That means the change remains stationary over time after the evaluated states. In the current study, this feature of the Markov Chain was used for the zero alternative of LUC change, i.e., for the historic trend description; while the planned change of the LUC condition, i.e., planned urban development, was used for the CDP alternative.

The assessment of LUC change in this research was limited to the three basic classes: a wet areas class was adopted as a proxy for wetlands and built-up and non built-up classes were used for urban development. The LUC simulation was based on the change of RS identified wet areas, though some amount of dried wetlands could have be classified as non built-up class due to the difference in environmental conditions over time. However, the intention was to show the applicability of the Markov Chain approach for scenario development and analysis in SEA practice. For practitioner's needs, the classification scheme can be adjusted depending on desired information resolution and can include, for example, dried wetlands and agriculture field classes separately.

The zero alternative simulated the tendency of urban development before prescribed urban planning and development actions have taken place, while the CDP alternative simulated future LUC in order to account for prescribed development plans and wetland conservation initiatives. Overall, results for the year 2043 under the CDP and zero LUC simulations were similar. In the context of wetlands management, this suggests that the application of the current wetland conservation strategy, only within administrative based planning units, will not be sufficient to compensate for the historic trend of wetland area decrease in the city. However, the variability analysis of difference between the current development strategy and the historical trend wet areas simulations (the CDP and the zero alternatives) identified areas of positive and negative difference. The areas with positive differences are located at the north-east of the city and might experience improvements in wetland coverage due to conservation initiatives; the rest of the Study Area does not have a wetland benefit in terms of wetland conservation. The variability is most likely a reflection of a difference in landscape wetland/urban spatial patterns that was not fully considered in development planning. Overall, for wetland conservation policy improvement, it is suggested that: (i) any wetland conservation strategy should consider wetland functional scale and 
ecologically meaningful units, e.g., water catchments, as opposed to solely administrative based planning units; and (ii) a variable conservation rate based on consideration of the particular qualities and variability of the LUC (e.g., existing wetland area and wetland/urban spatial patterns) is preferred to a standard conservation prescription across the urban area.

The scenario-based approach presented in this work provides a basis for wetland trends and future LUC analysis, which, in future practice, may be extended by using a range of alternatives; for example, based on modeled planning documentation with respective desired outcomes that may involve different urban development plans, different patterns of urban growth and density, and alternatives wetland conservation policies or targets. Despite the frequent lack of consistency in input data for undertaking such quantitative-based analysis in urban wetland contexts, the approach presented here utilizes a reliable and replicable method for futures analysis that can be contextualized for wetland conservation. This research may be used to support urban planners and wetland policy makers in the development and comparison of completing planning, development, and land use zoning options to help ensure that urban wetland conservation goals are achieved.

\section{Conclusions}

This paper presented an approach for the assessment of urban planning futures in the context of urban wetland conservation. The research was designed as a scenario planning exercise, where two alternatives, a zero alternative and current development plan alternative, described potential wetland futures based on past trends of urban development and wetland change. The study addresses the currently recognized need for contextualized methodology in SEA to support scenario development and LUC modeling [26-28], particularly within the context of wetland conservation. The scenario exercise did reveal some shortcomings and difficulties in on-the-ground application, specifically related to assessment contextualization, data quality, data availability, and data consistency. The approach presented in this paper may be useful for SEA practitioners, whose work is related to wetland and urban growth analysis, in environmental assessment and leverage data and information that can be helpful in development plan design, in the comparison and revising of wetland conservation strategies, as well as in providing a sound basis for decision and policy making in urban environmental management.

\section{Acknowledgments}

The research was funded by the Natural Sciences and Engineering Research Council IPS2 grants program and Ducks Unlimited Canada. Data support was provided by Ducks Unlimited Canada, the City of Saskatoon, and the Rural Municipality of Corman Park No. 344. Additional gratitude to Chris Schulz, Senior Planner at the Planning and Development Branch, the City of Saskatoon, for his valuable comments and support.

\section{Author Contributions}

This work was led by Anton Sizo as a part of his PhD thesis, under the supervision of Bram Noble and Scott Bell. The data were collected and analyzed by Anton Sizo, and reviewed by Bram Noble and 
Scott Bell. All authors were equally involved in the writing of the manuscript for publishing. Anton Sizo generated all maps and figures. All authors read and approved the final manuscript.

\section{Conflicts of Interest}

The authors declare no conflict of interest.

\section{References}

1. Bartzen, B.A.; Dufour, K.W.; Clark, R.G.; Caswell, F.D. Trends in agricultural impact and recovery of wetlands in prairie Canada. Ecol. Appl. 2010, 20, 525-538.

2. Ehrenfeld, J.G. Evaluating wetlands within an urban context. Ecol. Eng. 2000, 15, 253-265.

3. Nielsen, J.; Noble, B.; Hill, M. Wetland assessment and impact mitigation decision support framework for linear development projects: The Louis Riel Trail, Highway 11 North project, Saskatchewan, Canada. Can. Geogr./Le Géographe Can. 2012, 56, 117-139.

4. Geneletti, D. Reasons and options for integrating ecosystem services in strategic environmental assessment of spatial planning. Int. J. Biodivers. Sci. Ecosyst. Serv. Manag. 2011, 7, 143-149.

5. Chaker, A.; El-Fadl, K.; Chamas, L.; Hatjian, B. A review of strategic environmental assessment in 12 selected countries. Environ. Impact Assess. Rev. 2006, 26, 15-56.

6. Thérivel, R. Strategic Environmental Assessment in Action; Earthscan: London, UK, 2004; p. 276.

7. Bidstrup, M.; Hansen, A.M. The paradox of strategic environmental assessment. Environ. Impact Assess. Rev. 2014, 47, 29-35.

8. Gunn, J.; Noble, B. A conceptual basis and methodological framework for regional strategic environmental assessment (R-SEA). Impact Assess. Proj. Apprais. 2009, 27, 258-270.

9. Castellani, V.; Sala, S. Sustainability Indicators Integrating Consumption Patterns in Strategic Environmental Assessment for Urban Planning. Sustainability 2013, 5, 3426-3446.

10. He, J.; Bao, C.-K.; Shu, T.-F.; Yun, X.-X.; Jiang, D.; Brwon, L. Framework for integration of urban planning, strategic environmental assessment and ecological planning for urban sustainability within the context of China. Environ. Impact Assess. Rev. 2011, 31, 549-560.

11. Westbrook, C.J.; Noble, B. Science requisites for cumulative effects assessment for wetlands. Impact Assess. Proj. Apprais. 2013, 31, 318-323.

12. Partidário, M.R. Strategic Environmental Assessment Better Practice Guide-Methodological Guidance for Strategic Thinking in SEA; Portuguese Environment Agency and Redes Energéticas Nacionais: Lisbon, Portugal, 2012.

13. Noble, B. Strategic approaches to regional cumulative effects assessment: A case study of the Great Sand Hills, Canada. Impact Assess. Proj. Apprais. 2008, 26, 78-90.

14. Canadian Council of Ministers of the Environment. Regional Strategic Environmental Assessment in Canada: Principles and Guidance; Canadian Council of Ministers of the Environment: Winnipeg, MB, Canada, 2009.

15. White, L.; Noble, B. Strategic environmental assessment for sustainability: A review of a decade of academic research. Environ. Impact Assess. Rev. 2013, 42, 60-66.

16. Geneletti, D. Environmental assessment of spatial plan policies through land use scenarios: A study in a fast-developing town in rural Mozambique. Environ. Impact Assess. Rev. 2012, 32, 1-10. 
17. Gontier, M. Scale issues in the assessment of ecological impacts using a GIS-based habitat model-A case study for the Stockholm region. Environ. Impact Assess. Rev. 2007, 27, 440-459.

18. Bonder, J.; Cherp, A. Quality review package for strategic environmental assessments of land-use plans. Impact Assess. Proj. Apprais. 2000, 18, 99-100.

19. The Assessment of the Effects of Certain Plans and Programmes on the Environment. European Parliament and Council Commission's Guidance on the implementation of Directive 2001/42/EC, 2003.

20. Schmidt, M.; João, E.; Albrecht, E. Implementing Strategic Environmental Assessment; Schmidt, M., João, E., Albrecht, E., Eds.; Springer Berlin: Heidelberg, Germany, 2005; Volume 2, p. 742.

21. Duinker, P.; Greig, L. Scenario analysis in environmental impact assessment: Improving explorations of the future. Environ. Impact Assess. Rev. 2007, 27, 206-219.

22. Peterson, G.D.; Cumming, G.S.; Carpenter, S.R. Scenario Planning: A Tool for Conservation in an Uncertain World. Conserv. Biol. 2003, 17, 358-366.

23. Zhu, Z.; Bai, H.; Xu, H.; Zhu, T. An inquiry into the potential of scenario analysis for dealing with uncertainty in strategic environmental assessment in China. Environ. Impact Assess. Rev. 2011, 31, 538-548.

24. Sohl, T.; Loveland, T.; Sleeter, B.; Sayler, K.; Barnes, C. Addressing foundational elements of regional land-use change forecasting. Landsc. Ecol. 2010, 25, 233-247.

25. Verburg, P.; Schot, P.; Dijst, M.; Veldkamp, A. Land use change modelling: Current practice and research priorities. Geo J. 2004, 61, 309-324.

26. Bragagnolo, C.; Geneletti, D. Dealing with land use decisions in uncertain contexts: A method to support Strategic Environmental Assessment of spatial plans. J. Environ. Plan. Manag. 2013, 57, 50-77.

27. Mozumder, C.; Tripathi, N.K. Geospatial scenario based modelling of urban and agricultural intrusions in Ramsar wetland Deepor Beel in Northeast India using a multi-layer perceptron neural network. Int. J. Appl. Earth Obs. Geoinf. 2014, 32, 92-104.

28. Ma, C.; Zhang, G.Y.; Zhang, X.C.; Zhao, Y.J.; Li, H.Y. Application of Markov model in wetland change dynamics in Tianjin Coastal Area, China. Procedia Environ. Sci. 2012, 13, 252-262.

29. Noble, B.; Gunn, J.; Martin, J. Survey of current methods and guidance for strategic environmental assessment. Impact Assess. Proj. Apprais. 2012, 30, 1-9.

30. Davidson, N.C.; Finlayson, C.M. Earth Observation for wetland inventory, assessment and monitoring. Aquat. Conserv. Mar. Freshw. Ecosyst. 2007, 17, 219-228.

31. Mitsch, W.J.; Gosselink, J.G. Wetlands, 4th ed.; John Wiley and Sons: Hoboken, NJ, USA, 2007.

32. National Wetlands Working Group; Canada Committee on Ecological Land Classification. Wetlands of Canada; Polyscience Publications Inc.: Montreal, QC, Canada, 1988.

33. Noble, B.; Hill, M.; Nielsen, J. Environmental assessment framework for identifying and mitigating the effects of linear development to wetlands. Landsc. Urban Plan. 2011, 99, 133-140.

34. Rubec, C.; Hanson, A. Wetland mitigation and compensation: Canadian experience. Wetl. Ecol. Manag. 2009, 17, 3-14.

35. Neuman, A.; Belcher, K. The contribution of carbon-based payments to wetland conservation compensation on agricultural landscapes. Agric. Syst. 2011, 104, 75-81.

36. Seitz, N.E.; Westbrook, C.J.; Noble, B. Bringing science into river systems cumulative effects assessment practice. Environ. Impact Assess. Rev. 2011, 31, 172-179. 
37. Veldkamp, A.; Verburg, P.H. Modelling land use change and environmental impact. J. Environ. Manag. 2004, 72, 1-3.

38. Schrojenstein Lantman, J.; Verburg, P.; Bregt, A.; Geertman, S. Core Principles and Concepts in Land-Use Modelling: A Literature Review. In Land-Use Modelling in Planning Practice SE-3; Koomen, E., Borsboom-van Beurden, J., Eds.; GeoJournal Library; Springer: Amsterdam, The Netherlands, 2011.

39. Zhang, R.; Tang, C.; Ma, S.; Yuan, H.; Gao, L.; Fan, W. Using Markov chains to analyze changes in wetland trends in arid Yinchuan Plain, China. Math. Comput. Model. 2011, 54, 924-930.

40. Arsanjani, J.J.; Helbich, M.; Kainz, W.; Boloorani, A.D. Integration of logistic regression, Markov chain and cellular automata models to simulate urban expansion. Int. J. Appl. Earth Obs. Geoinf. 2013, 21, 265-275.

41. Huel, D. Managing Saskatchewan Wetlands-A Landowner's Guide; Saskatchewan Wetland Conservation Corporation: Regina, SK, Canada, 2000.

42. City of Saskatoon Population Estimate \& Projection. Available online: http://www.saskatoon.ca/ departments/communityservices/planningdevelopment/futuregrowth/demographicandhousingdata/ Pages/PopulationEstimateProjection.aspx (accessed on 26 July 2014).

43. City of Saskatoon. City of Saskatoon Municipal Manual 2011; City of Saskatoon: Saskatoon, SK, Canada, 2011.

44. Statistics Canada; Census of Canada. Saskatchewan Population Report; Saskatchewan Bureau of Statistic, Ministry of Finance: Regina, SK, Canada, 2011.

45. City of Saskatoon. City of Saskatoon Future Growth Study 2000; City of Saskatoon: Saskatoon, SK, Canada, 2000.

46. City of Saskatoon. City of Saskatoon City of Saskatoon \& Saskatoon Census Metropolitan Area Population Projection 2012-2032; City of Saskatoon: Saskatoon, SK, Canada, 2013.

47. City of Saskatoon. City of Saskatoon The Official Community Plan Bylaw; No. 8769; City of Saskatoon: Saskatoon, SK, Canada, 2009.

48. City of Saskatoon Sector Planning. Available online: http://www.saskatoon.ca/departments/ Community Services/PlanningDevelopment/FutureGrowth/Sector Planning/Pages/default.aspx (accessed on 21 April 2014).

49. Sizo, A.; Noble, B.; Bell, S. Strategic environmental assessment framework for landscape-based, temporal analysis of wetland change in urban environments. Environ. Manag. 2015, submitted.

50. Duinker, P.; Greig, L. The impotence of cumulative effects assessment in Canada: Ailments and ideas for redeployment. Environ. Manag. 2006, 37, 153-161.

51. Committee on Mitigating Wetland Losses; Board on Environmental Studies and Toxicology; Water Science and Technology Board; National Research Council. Compensating for Wetland Losses Under the Clean Water Act; The National Academy Press: Washington, DC, USA, 2001; p. 322.

52. Fischer, T.B. The Theory and Practice of Strategic Environmental Assessment: Towards a More Systematic Approach; Earthscan: London, UK, 2007.

53. Thérivel, R.; Caratti, P.; Partidário, M.R.; Theodórsdóttir, Á.H.; Tyldesley, D. Writing strategic environmental assessment guidance. Impact Assess. Proj. Apprais. 2004, 22, 259-270.

54. Wright, F. Consideration of the baseline environment in examples of voluntary SEAs from Scotland. Environ. Impact Assess. Rev. 2007, 27, 424-439. 
55. Ramsar Convention Secretariat. Impact Assessment: Guidelines on Biodiversity-Inclusive Environmental Impact Assessment and Strategic Environmental Assessment, 4th ed.; Ramsar Convention Secretariat: Gland, Switzerland, 2010; Volume 16, p. 67.

56. Privy Council Office, Government of Canada. The cabinet Directive on the Environment Assessment of Policy, Plan and Program Proposals 2010; Canadian Environmental Assessment Agency: Ottawa, ON, Canada, 2010.

57. Gala, T.S.; Melesse, A.M. Monitoring prairie wet area with an integrated LANDSAT ETM ${ }^{+}$, RADARSAT-1 SAR and ancillary data from LIDAR. CATENA 2012, 95, 12-23.

58. MacGregor-Fors, I. Misconceptions or misunderstandings? On the standardization of basic terms and definitions in urban ecology. Landsc. Urban Plan. 2011, 100, 347-349.

59. USGS. Product Guide: Landsat 4-7 Climate Data Record (CDR) Surface Reflectance 2014; USGS: Reston, VA, USA, 2014.

60. Dahl, T.E.; Watmough, M.D. Current approaches to wetland status and trends monitoring in prairie Canada and the continental United States of America. Can. J. Remote Sens. 2007, 33, S17-S27.

61. Rebonato, R.; Jackel, P. The most general methodology to create a valid correlation matrix for risk management and option pricing purposes. J. Risk 2000, 2, 17-28.

62. Chun, K.P.; Wheater, H.S. An extreme analysis for the 2010 precipitation event at the South of Saskatchewan Prairie. Glob. NEST J. 2012, 14, 311-324.

63. Mitsch, W.J.; Gosselink, J.G. The value of wetlands: Importance of scale and landscape setting. Ecol. Econ. 2000, 35, 25-33.

64. Kristensen, S.; Noble, B.; Patrick, R.J. Capacity for Watershed Cumulative Effects Assessment and Management: Lessons from the Lower Fraser River Basin, Canada. Environ. Manag. 2013, 52, 360-373.

65. González, A.; Gilmer, A.; Foley, R.; Sweeney, J.; Fry, J. Applying geographic information systems to support strategic environmental assessment: Opportunities and limitations in the context of Irish land-use plans. Environ. Impact Assess. Rev. 2011, 31, 368-381.

66. João, E. A research agenda for data and scale issues in Strategic Environmental Assessment (SEA). Environ. Impact Assess. Rev. 2007, 27, 479-491.

67. MacDonald, L.H. Evaluating and Managing Cumulative Effects: Process and Constraints. Environ. Manag. 2000, 26, 299-315.

68. Winston, W.L. Operations Research: Applications and Algorithms, 3rd ed.; Wadsworth Publishing Company: Belmont, CA, USA, 1997.

(C) 2015 by the authors; licensee MDPI, Basel, Switzerland. This article is an open access article distributed under the terms and conditions of the Creative Commons Attribution license (http://creativecommons.org/licenses/by/4.0/). 